\title{
COVID-19 Pandemic: A Physiotherapy Update
}

\author{
Paolo Pedersini ${ }^{1^{\star}}$, Jorge Hugo Villafañe ${ }^{1}$, Camilo Corbellini ${ }^{2,3}$, Marcos Roberto Tovani-Palone ${ }^{4^{*}}$
}

\author{
${ }^{1}$ IRCCS Fondazione Don Carlo Gnocchi, Milan, ITALY \\ ${ }^{2}$ Casa di Cura Villa Serena, Piossasco, ITALY \\ ${ }^{3}$ LUNEX International University of Health, Exercise and Sports, Department of Physiotherapy, LUXEMBOURG \\ ${ }^{4}$ Ribeirão Preto Medical School, University of São Paulo, Ribeirão Preto, BRAZIL \\ *Corresponding Author: pedersini93@gmail.com \\ ${ }^{\star \star}$ Corresponding Author: marcos_palone@hotmail.com
}

Citation: Pedersini P, Villafañe JH, Corbellini C, Tovani-Palone MR. COVID-19 Pandemic: A Physiotherapy Update. Electron J Gen Med. 2021;18(1):em264. https://doi.org/10.29333/ejgm/8574

\section{ARTICLE INFO}

Received: 17 Jun. 2020

Accepted: 4 Aug. 2020

\begin{abstract}
Physiotherapists have an essential role in the recovery of patients who require hospital care and/or in intensive care units. However, so far, there is little discussion in literature about the interventions by physiotherapists together with multidisciplinary teams in hospital units that receive COVID-19 patients. In this perspective article, we discuss the role and importance of physiotherapy in the management of COVID-19 cases with focus on patients admitted to hospitals.
\end{abstract}

Keywords: coronavirus, rehabilitation, pandemics, physical therapists, hospitals, critical care

\section{INTRODUCTION}

Current data show that the total number of confirmed cases of coronavirus disease 2019 (COVID-19) due to severe acute respiratory syndrome coronavirus 2 (SARS-CoV-2) in the world exceeds 11,8 million cases, resulting in more than 543,558 deaths [1]. In some countries of the American continent, such as Brazil, confirmed cases of the disease have been growing seriously in a classic exponential curve and with a rapid daily rate, with more negative forecasts compared to European countries, like Italy and Spain [2]. Given the limited capacity of health systems to assist COVID-19 patients, it is essential in this context to flatten the epidemic curve of the disease in order to avoid possible overload and collapses in the health sector $[2,3]$. Moreover, the expansion of the COVID-19 pandemic in some countries has brought additional concerns, as in the case of Brazil, where, at the same time at least two more epidemics (dengue and influenza) have occurred [4,5].

Due to this situation, governments and public health authorities around the world have taken several decisions on an emergency basis in order to slow down the rise of new cases of COVID-19, as well as to decrease the number of related deaths. Initially, restricted measures, including social isolation, have been implemented in several countries with the aim of containing the rapid spread of the virus $[2,6,7]$, which has undoubtedly generated various negative social, economic, and political impacts [8]. In this scenario, health systems are facing an abrupt increase in demand for intensive care, specifically aimed at preserving the lives of thousands of people with COVID-19 [7]. Thus, the existence of highly trained multidisciplinary teams in health units, following evidencebased recommendations, may be crucial for a better management of the disease. Recent research suggests that physiotherapy team has an essential role in the recovery of patients who require hospital care and/or in intensive care units (ICU) [9]. However, so far, there is little discussion in literature about the interventions by physiotherapists together with multidisciplinary teams in hospital units that receive COVID-19 patients. Here, we discuss the role and importance of physiotherapy in the management of COVID-19 cases with focus on patients admitted to hospitals.

\section{PHYSIOTHERAPY AND COVID-19 SPREAD}

As COVID-19 spreads all across the world, the rehabilitation community had to respond to the challenges associated with this emergency. In a scenario characterized by no evidence of any effective treatment for COVID-19, a reorganization of the work and an adaptation of health care interventions were necessary. Predicting the disease from the symptoms onset was hard considering furthermore the fast contagion spread through a community transmission among human and through contact with contaminated environmental surfaces [10]. The real challenge has been responding and understanding how to prepare workplaces and to organize the clinical routines in order to receive potentially infected subjects. The rehabilitation community as well as the other professional health care providers have been called to optimize their clinical practice to face the COVID-19 diffusion [11]. Most countries around the world have seen COVID-19 cases and many are experiencing outbreaks of the disease. Because of that, the World Health Organization has provided countermeasures producing guidelines for the clinical daily life context [12].

ICU, in turn, is playing a vital role in this epidemic. With the aim of facing this emergency, entire hospital wards have been transformed in ICU to host patients requiring ventilatory care. 
The respiratory physiotherapy in ICU contributes to improve oxygenation in mechanically ventilated patients with severe acute respiratory failure or acute respiratory distress syndrome [13]. As it is known, COVID -19 patients can present a severe ventilation/perfusion mismatch, which could be overcome by positioning the patient in prone position [14]. In this connection, this treatment strategy also matters to the physiotherapist practice. Despite this, specific data supporting the rehabilitative care for ICU COVID-19 patients are lacking, and current recommendations are based only on existing evidence from other viral respiratory infections and general intensive care management.

It is therefore important to highlight the crucial role that physiotherapists have in the management of patients admitted with suspicion or confirmation of the disease in COVID-19 hospitals. Several countermeasures have been implemented in a recent publication sharing the guidelines and clinical practice recommendations in the hospital setting [15].

\section{THE BENEFITS OF PHYSICAL THERAPY FOR ICU COVID-19 PATIENTS}

Both trained respiratory and musculoskeletal physiotherapists are actively involved in the management of ICU COVID-19 patients. A series of clinical guidelines for the prevention and treatment of adult patients in ICU are currently present in literature, highlighting the importance of pain, agitation/sedation, delirium, immobility, and sleep disruption management [16]. The COVID-19 disease primarily affects the lungs, causing interstitial pneumonitis and severe acute respiratory distress syndrome. The acute hypoxemic patients may experience dyspnea, which can require the administration of oxygen flows. The benefits of pulmonary rehabilitation practice have been reported and they include the use of some devices, such as high flow nasal oxygen [17], application of continuous positive airways pressure (CPAP) [18], or noninvasive ventilation [19]. In addition, a potential rapid worsening of hypoxemia with the subsequent need of intubation and invasive mechanical ventilation has to be taken into account in patients affected by COVID-19 [20]. Thus, the role of the physiotherapist become also essential in a context where a huge number of patients required ICU hospitalization, and in several cases, the use of invasive mechanical ventilation. The main goals in this case are optimizing ventilation and oxygenation; improving compliance and ventilation/perfusion mismatch, reducing work of breathing; decreasing ventilator dependence and improving residual function; improving respiratory muscle strength and reducing complications [8]. The post-acute setting of the disease also represents an important issue to be better understood. The needs of the COVID-19 survivors may vary from a person to another and until now most of the information already published has been based in expert opinion papers, mostly from China or Italy [21]. Therefore, all the previously mentioned points in this manuscript should be of great importance for the recovery of COVID-19 patients [9].

Another critical topic in ICU COVID-19 patients has been discussed in a recent paper: the risk of thromboembolism [22]. Critically ill patients are at high risk of venous thromboembolism because they combine both general risk factors together with specific ICU risk factors. The American Physical Therapy Association (APTA), in cooperation with the
Cardiovascular \& Pulmonary and Acute Care sections of APTA, provided in 2016 clinical practice guidelines to assist physiotherapists in their decision-making process, with an emphasis on patients at risk for venous thromboembolism or diagnosed with a lower extremity deep vein thrombosis [23].

Complementary to this, recent evidence supports the safety, feasibility, and benefits of early mobilization and rehabilitation of mechanically ventilated patients [24]. ICUacquired weakness is an increasingly recognized problem, with sequelae that may last for months and years following discharge [25]. Furthermore, the combination of critical illness and bed rest results in substantial muscle wasting during an ICU stay. Shortly after the beginning of the mechanical ventilation, mobilization and rehabilitation can play an essential role in decreasing both the duration of mechanical ventilation and hospital stay, improving patients' return to functional independence. Active mobilization and rehabilitation in the ICU have no impact on short- and longterm mortality, but they may improve mobility status, muscle strength, days alive, and out of the hospital to 180 days [26].

Given the urgency and novelty of this pandemic, the rehabilitative care deserves particular consideration due to the potential impacts of mobilization and rehabilitative therapies on morbidity, mortality, duration of ventilation, and lengths of ICU/hospital stay.

\section{THE POST-ACUTE PHASE OF THE DISEASE}

Post-acute COVID-19 patients are considered individuals with a post-intensive care syndrome (PICS) resulting in the loss of functional independence. A recent study determined that ICU patients require 1-year recovery and healthcare use [27]. Besides, an increasing number of ICU patients have survived and developed psychological, cognitive, or physical impairment. As a result of the ICU stay, the recovery of COVID19 patients with impaired respiratory and physical functions may take a long time after discharge, leading to a reduction in quality of life. COVID-19 survivors, particularly those who developed severe respiratory symptoms and had prolonged ICU stay, require rehabilitation care, because of their cardiorespiratory and musculoskeletal problems [28]. In this sense, one of the most essential aims of physiotherapists is to help patients to recover the ability to perform the daily life activities, developing different rehabilitation programs, depending on the severity of critical illness and individual goals [29] . Muscle wasting and weakness are significant contributors to PICS and are associated with greater disability, extended hospitalization, and increased post-ICU mortality making their management a challenge for the physical rehabilitation experts [30].

Physiotherapists, therefore, will have a key role in providing exercise, mobilization, and rehabilitation interventions to COVID-19 survivors in order to enable a functional return to home [31]. In view of this, the crucial importance of the rehabilitation has led to creation of innovative approaches during the pandemic. In this new scenario, inpatient rehabilitation populations became a more vulnerable group, so that the virtual care has been preferred in relation to face-to-face interaction to avoid the infection spreading [32].

It is also worth mentioning, in this regard, that a position statement paper has defined the role of exercise on enhancing 
the immune function [33], promoting a global positive immune response. Based on these circumstances, it is fundamental to start an early rehabilitation right after the COVID-19 acute phase, to limit the severity of ICU-acquired weakness and promote a rapid functional recovery [34].

\section{CONCLUSION}

COVID-19 outbreak is the most important health emergency in recent decades, an event of exceptional magnitude, which has required the implementation of extraordinary countermeasures, ranging from the reorganization of the hospital network, to the quarantine of entire countries. There are many issues to be analyzed in this emergency. First of all, now it became clear that a robust public health care system, with solid prevention strategies, makes the difference in situations such as this. Preparations must focus not only on infrastructure and supplies, but also on staff, including protection from nosocomial transmission and promotion of mental wellbeing [35]. Many lessons can be learnt from the cumulative experience and the role of physiotherapy in this pandemic. In this sense, the work of physiotherapists may be beneficial in the respiratory treatment and physical rehabilitation of COVID-19 patients.

Author contributions: All authors have sufficiently contributed to the study, and agreed with the results and conclusions.

Funding: No funding source is reported for this study.

Declaration of interest: No conflict of interest is declared by authors.

\section{REFERENCES}

1. Johns Hopkins Coronavirus Resource Center. World Map. Baltimore. Availabe at: https://coronavirus.jhu.edu/ map.html (Accessed: 14 June 2020).

2. Serdan TDA, Masi LN, Gorjao R, Pithon-Curi TC, Curi R, Hirabara SM. COVID-19 in Brazil: historical cases, disease milestones, and estimated outbreak peak. Travel Med Infect Dis. 2020;101733. https://doi.org/10.1016/ j.tmaid.2020.101733 PMid:32407892 PMCid:PMC7214305

3. Oliveira WK, Duarte E, França GVA, Garcia LP. How Brazil can hold back COVID-19. Epidemiol Serv Saude. 2020;29(2):e2020044. https://doi.org/10.5123/S167949742020000200023

4. Brazil. Ministry of Health. Health Surveillance Secretariat. Epidemiological bulletin 19 [Boletim epidemiológico 19]. Brasília: Ministry of Health; 2020. Available at: https://www.saude.gov.br/images/pdf/2020/April/16/Bole tim-epidemiologico-SVS-16.pdf (Accessed: 1 June 2020).

5. Brazil. Ministry of Health. Public Health Emergency Operations Center. Daily epidemiological bulletin [Boletim epidemiológico diário]. Brasília: Ministry of Health; 2020. Available at: https://www.saude.gov.br/images/pdf/2020/ April/20/20.04.2020_COVID1.pdf (Accessed: 1 June 2020).

6. Nafees M, Khan F. Pakistan's response to COVID-19 pandemic and efficacy of quarantine and partial lockdown: a review. Electron J Gen Med. 2020;17(6): em240. https://doi.org/10.29333/ejgm/7951

7. Santacroce L, Charitos IA, Del Prete R. COVID-19 in Italy: an overview from the first case to date. Electron J Gen Med. 2020;17(6):em235. https://doi.org/10.29333/ejgm/7926
8. Yezli S, Khan A. COVID-19 social distancing in the Kingdom of Saudi Arabia: bold measures in the face of political, economic, social and religious challenges. Travel Med Infect Dis. 2020;101692. https://doi.org/10.1016/j.tmaid. 2020.101692 PMid:32330561 PMCid:PMC7172679

9. Jang $M H$, Shin MJ, Shin YB. Pulmonary and physical rehabilitation in critically ill patients. Acute Crit Care. 2019;34(1):1-13. https://doi.org/10.4266/acc.2019.00444 PMid:31723900 PMCid:PMC6849048

10. Pascarella G, Strumia A, Piliego C, et al. COVID-19 diagnosis and management: a comprehensive review. J Intern Med. 2020. https://doi.org/10.1111/joim.13091 PMid:32348588 PMCid:PMC7267177

11. Pedersini P, Corbellini C, Villafañe JH. Italian physical therapists' response to the novel COVID-19 emergency. Phys Ther. 2020;pzaa060. https://doi.org/10.1093/ptj/ pzaa060 PMid:32280973 PMCid:PMC7184495

12. World Health Organization. Country \& technical guidance coronavirus disease (COVID-19). Genebra: World Health Organization; 2020. Available at: https://www.who.int/ emergencies/diseases/novel-coronavirus-2019/technicalguidance (Accessed: 14 June 2020).

13. Stiller K. Physiotherapy in intensive care: towards an evidence-based practice. Chest. 2000;118(6):1801-13. https://doi.org/10.1378/chest.118.6.1801 PMid:11115476

14. Santamarina MG, Boisier D, Contreras R, Baque M, Volpacchio M, Beddings I. COVID-19: a hypothesis regarding the ventilation-perfusion mismatch. Crit Care. 2020;24(1):395. https://doi.org/10.1186/s13054-020-031259 PMid:32631389 PMCid:PMC7338110

15. Thomas $P$, Baldwin C, Bissett B, et al. Physiotherapy management for COVID-19 in the acute hospital setting: clinical practice recommendations. J Physiother. 2020;66(2):73-82. https://doi.org/10.1016/j.jphys.2020.03. 011 PMid:32312646 PMCid:PMC7165238

16. Devlin JW, Skrobik Y, Gélinas C, et al. Clinical practice guidelines for the prevention and management of pain, agitation/sedation, delirium, immobility, and sleep disruption in adult patients in the ICU. Crit Care Med. 2018;46(9):e825-e873.

17. Frat JP, Thille AW, Mercat A, et al. High-flow oxygen through nasal cannula in acute hypoxemic respiratory failure. $\mathrm{N}$ Engl J Med. 2015;372(23):2185-96. https://doi.org/10.1056/ NEJMoa1503326 PMid:25981908

18. Andrews PL, Shiber JR, Jaruga-Killeen E, et al. Early application of airway pressure release ventilation may reduce mortality in high-risk trauma patients: a systematic review of observational trauma ARDS literature. J Trauma Acute Care Surg. 2013; 75(4): 635-41. https://doi.org/ 10.1097/TA.0b013e31829d3504 PMid:24064877

19. Sun X, Liu Y, Li N, You D, Zhao Y. The safety and efficacy of airway pressure release ventilation in acute respiratory distress syndrome patients: a PRISMA-compliant systematic review and meta-analysis. Medicine (Baltimore). 2020 ;99(1):e18586.

https://doi.org/10.1097/MD.0000000000018586 PMid:31895807 PMCid:PMC6946469

20. Lazzeri M, Lanza A, Bellini R, et al. Respiratory physiotherapy in patients with COVID-19 infection in acute setting: a position paper of the Italian Association of Respiratory Physiotherapists (ARIR). Monaldi Arch Chest Dis. 2020;90(1). https://doi.org/10.4081/monaldi.2020. 1285 
21. Tovani-Palone MR, Storari L, Barbari V. Could preventing thromboembolism be a new hope for COVID-19 patients? Electron J Gen Med. 2020;17(6):em250. https://doi.org/ 10.29333/ejgm/8244

22. Sheehy LM. Considerations for postacute rehabilitation for survivors of COVID-19. JMIR Public Health Surveill. 2020;6(2):e19462. https://doi.org/10.2196/19462 PMid: 32369030 PMCid:PMC7212817

23. Hillegass E, Puthoff M, Frese EM, et al. Role of physical therapists in the management of individuals at risk for or diagnosed with venous thromboembolism: evidencevased clinical practice guideline. Phys Ther. 2016;96(2):14366. https://doi.org/10.2522/ptj.20150264 PMid:26515263

24. Hashem MD, Nelliot A, Needham DM. Early mobilization and rehabilitation in the ICU: moving back to the future. Respir Care. 2016;61(7):971-9. https://doi.org/10.4187/ respcare.04741 PMid:27094396

25. Smith JM, Lee AC, Zeleznik H, et al. Home and communitybased physical therapist management of adults with postintensive care syndrome. Phys Ther. 2020;pzaa059. [Epub ahead of print]

26. Tipping CJ, Harrold M, Holland A, Romero L, Nisbet $T$, Hodgson CL. The effects of active mobilisation and rehabilitation in ICU on mortality and function: a systematic review. Intensive Care Med. 2017;43(2):171-83. https://doi.org/10.1007/s00134-016-4612-0 PMid:27864615

27. Herridge MS, Chu LM, Matte A, et al. The RECOVER program: disability risk groups and 1-Year outcome after 7 or more days of mechanical ventilation. Am J Respir Crit Care Med. 2016;194(7):831-44. https://doi.org/10.1164/rccm.20151223430C PMid:26974173

28. Stam HJ, Stucki G, Bickenbach J. Covid-19 and post intensive care syndrome: a call for action. J Rehabil Med. 2020;52(4):jrm00044. https://doi.org/10.2340/165019772677 PMid:32286675
29. Thomas S, Mehrholz J, Bodechtel U, Elsner B. Effect of physiotherapy on regaining independent walking in patients with intensive-care-unit-acquired muscle weakness: a cohort study. J Rehabil Med. 2019;51(10):797804. https://doi.org/10.2340/16501977-2606 PMid: 31544216

30. Connolly B, Salisbury L, O'Neill B, et al. Exercise rehabilitation following intensive care unit discharge for recovery from critical illness. Cochrane Database Syst Rev. 2015;2015(6):CD008632.

https://doi.org/10.1002/14651858.CD008632.pub2 PMid:26098746 PMCid:PMC6517154

31. Verceles AC, Wells CL, Sorkin JD, et al. A multimodal rehabilitation program for patients with ICU acquired weakness improves ventilator weaning and discharge home. J Crit Care. 2018;47:204-10. https://doi.org/10.1016/ j.jcrc.2018.07.006 PMid:30025227 PMCid:PMC6143437

32. Walsh NP, Gleeson M, Shephard RJ, et al. Position statement. part one: immune function and exercise. Exerc Immunol Rev. 2011;17:6-63.

33. Simpson R Robinson L. Rehabilitation after critical illness in people with COVID-19 infection. Am J Phys Med Rehabil. 2020;99(6):470-4. https://doi.org/10.1097/PHM.000000000 0001443 PMid:32282359 PMCid:PMC7253039

34. Pancera S, Galeri S, Porta R, et al. Feasibility and efficacy of the pulmonary rehabilitation program in a rehabilitation center: case report of a young patient developing severe COVID-19 acute respiratory distress syndrome. J Cardiopulm Rehabil Prev. 2020;40(4):205-8. https://doi.org/10.1097/HCR.0000000000000529 PMid:32609464

35. Torales J, O'Higgins M, Castaldelli-Maia JM, Ventriglio A. The outbreak of COVID-19 coronavirus and its impact on global mental health. Int J Soc Psychiatry. 2020 ;66(4):31720. https://doi.org/10.1177/0020764020915212 PMid: 32233719 